\title{
Knowledge and the preventive strategies of Malaria among Migrant Farmers in Ado-Ekiti Local Government Area of Ekiti State, Nigeria
}

\author{
Adegun Joel A., Adegboyega, J.A. and Awosusi Ajoke O., \\ Human Kinetics and Health Education Unit, University of Ado-Ekiti. Ekiti State, Nigeria.
}

\begin{abstract}
The aim of this study was to investigate the knowledge and the preventive strategies of malaria among migrant farmers in Ado-Ekiti Local Government Area of Ekiti State, Nigeria. The study was a descriptive design of the survey type. The structured questionnaire used for this study was adapted from Matta, Khokhar and Sachdev (2004). The instrument with detailed information on knowledge of malaria disease, the preventive strategies and practice of the preventing strategies was used to elicit information from the participants. Five (5) farm settlements were randomly selected from the existing twenty five (25) locations in Ado Ekiti Local Government Area and a total of sixty respondents were randomly selected from each farm settlement giving a total of 300 migrant farmers that were used for the study. The research instrument was administered to the participants by the researchers and trained research assistants who also helped in the interpretation of the items in the instrument in the local languages for those who did not understand English Language. Three hundred (300) questionnaires were administered and same were retrieved, collated and analyzed giving a 100\% returned rate. Both descriptive and inferential statistics were used to analyze the data. The descriptive analyses included frequency counts while t test and Analysis of Variance (ANOVA) were used to test hypotheses at 0.05 level of significance. The study revealed that the participants had adequate knowledge of malaria related issues and the preventive strategies. The knowledge of preventive strategies was significantly related with the practices of the preventive strategies among the migrant farmers. It was thus recommended that health education and sensitization programmes should be intensified to create more awareness on malaria prevention so that the populace will improve on their practices of malaria preventive strategies.
\end{abstract}

Keywords: Knowledge, Malaria, Migrant farmers and Preventive strategies.

\section{INTRODUCTION}

Malaria remains one of the major causes of morbidity and mortality in Sub-Saharan Africa because the environment favours the multiplication and sustenance of the parasite causing the disease. Malaria, a vector borne disease, transmitted by anopheles mosquito is an endemic disease in Nigeria. Sharma, Bhasin and Chaturvedi (2007) reported that a French scientist named Laveron discovered the malaria parasite over 125 years ago. Yet, malaria continues to be the world most important tropical disease and a leading public health problem. Despite the increasing research on malaria, the discovery of new drugs and vaccines including the various preventive strategies, Khan, Usman, Abbass, Hussain and Ali (2010) submitted that malaria still remains a significant cause of human morbidity and mortality. Malaria remains the major cause of admission in the health centres especially among children under five years and pregnant women. The burden of disease ascribed to malaria according to Lucas and Giles (2003) amount to 300-500 million clinical cases every year worldwide with over $80 \%$ occurring in Africa. It was also reported that in Africa, an estimate of one million people die from malaria each year with $90 \%$ of the deaths occurring in subSaharan Africa while 300,000 deaths from malaria occur in Nigeria every year (Oyewole and Ibidapo, 2007)

Malaria disease was formerly widespread but was successfully eliminated from many countries with temperate climates in the mid- $20^{\text {th }}$ century. Today, about $40 \%$ of the world's population especially those living in the world's poorest countries is at risk of malaria as the disease has become endemic in the tropical and sub-tropical regions of the world.

The factors determining the epidemiology of malaria, according to Lucas and Giles (2003), are 
environment, vector, parasites and the host factors. Temperature, humidity and rainfall are also important for malaria transmission. For instance, a high humidity is necessary for survival of adult vectors while rainfall is needed in the breeding sites. Kinung et al. (2010) linked the spread of malaria to environmental changes and increased rainfall coupled with ambient temperature, changes in land use pattern, malarial vector dynamics, host immune status and individual or community factors such as the socio-economic status, knowledge of malaria and the protective behaviour. However, the threat of global warming may lead to resurgence of the disease in temperate areas that have successfully eliminated the disease.

The scourge of malaria, for now, remains a health burden in the Tropics. Clinical manifestations of malaria have been identified as fever, rigor, headache, loss of appetite and general weakness of the body (Khan et al., 2010). Description of the physical and mental effects of malaria according to IRIN (2011) is fatigue, blurred vision, weakness and inability to concentrate all of which can reduce a person's productivity level. For farmers, malaria can reduce days spent in the farm leading to poor crops, meagre harvest and poverty. In addition, Lucas and Giles (2003) discovered that untreated malaria could result into hepatomegaly, splenomegaly, varying degree of anemia and various syndromes resulting from the involvement of individual organs.

The burden of malaria became so evident that United Nations Children Fund (UNICEF) in 1998 launched Roll Back malaria (RBM) initiative in Geneva. Also, the United Nations, at the Millennium Conference in New York in 2000 identified the reduction of morbidity and mortality caused by malaria as part of the measures to reduce poverty. Thus, combating HIV and AIDS, malaria and other diseases was listed as the $6^{\text {th }}$ Millennium Development Goals. This was aimed at halting and reversing the incidence of malaria by year 2015. To achieve the goal, National Health Policy (2002) cited in Sharma et al. (2010) set goal of reducing malaria by $50 \%$ in 2010 through efficient control of morbidity.

In Nigeria, migrant farmers often known for their seasonal movements, live in remote locations while majority of them reside in farm settlements where there are few or absence of social amenities such as electricity, water supply, good roads and health facilities among others. They contribute immensely to the economic growth of the communities where they work and live yet the seasonality of their movement, the low literacy and skill level and poor income from their produce have continually subjected them to poor living conditions. The economic situation in Nigeria has made it difficult for a low income resident to own a decent and comfortable house let alone a poor migrant farmer. Johansson, Renshaw and Wardlaw (2009) submitted that malaria is a disease of poverty afflicting people such as the poor who live in malaria prone rural areas and in poorly constructed dwellings that cannot prevent mosquito.

The situations around migrant farmers may suggest the likelihood of low knowledge of malaria disease though, Batega (2004) found that $80-90 \%$ of migrant farmers had the knowledge of the cause of malaria. The review of Udonwa, Gyuse and Etokidem (2010) reported that some surveys revealed lack of knowledge and many misconceptions about the transmission of malaria. In the survey, $86 \%$ of the respondents knew that malaria could be prevented which almost correspond with the findings of Rissa (2000) that $87.5 \%$ of a community knew that malaria can be prevented while $95.4 \%$ saw malaria as a severe problem that could kill. The knowledge of malaria preventive strategies can play an important role in preventing malaria, but the knowledge of these strategies seems to be low especially among migrant farmers. For instance, Fawole and Onyeaso (2008) discovered that the knowledge of farmers on malaria preventive measures was poor but Erhun, Agbani and Adesanya (2005) in a study discovered that a high percentage (86.5\%) knew about malaria preventive strategies.

In ensuring a sustainable preventive strategy, the participation of the community should be included at the planning stage. Khan et al. (2010) opined that failure to consider community attitude and beliefs about malaria has contributed to the failure in achieving sustainable malaria control strategies as direct interaction with the community would play a significant role in controlling the spread of malaria. Community participation, according to Sharma et al. (2010), depends on people's knowledge and attitude towards the disease. Thus, it is of utmost importance to investigate the current knowledge of the migrant farmers regarding malaria and the practice of the preventive strategies.

General Objective of Study: The general objective of the study is to determine the knowledge of malaria and as well as malaria preventive strategies among migrant farmers in Ado-Ekiti Local Area of Ekiti State, Nigeria. 


\section{HYPOTHESIS}

The following hypotheses were tested in the study

i. There is no significant difference between knowledge of malaria and knowledge of preventive strategies among migrant farmers in the study area.

ii. There is no significant difference between knowledge of malaria and practice of preventive strategies among migrant farmers in the study area.

iii. Educational status has no significant influence in the practice of malaria preventive strategies among migrant farmers

\section{METHODOLOGY}

The descriptive research of the survey type was used for the study. Adult migrant farmers residing in twenty five farm settlements in Ado Ekiti Local Government Area made up the study population. Ado Ekiti Local Government Area of Ekiti State is one of the 5 local Government Areas in Ekiti Central Senatorial District. Ado Ekiti doubles as the Ekiti State capital as well as the Headquarter of Ado Ekiti Local Government Area. The Local Government is made up of only one city. However, there are many villages and farm settlements within the local government. The villages and farm settlements are inhabited by farmers who practise commercial and subsistence farming. The farmers are skilled in the cultivation of yams, maize, cassava and other cash crops. Majority of the farmers are Ebira, Igalas from Kogi State, Igedes from Benue State and a few Urhobos from Delta State of Nigeria. The attraction for the migrant farmers to concentrate in the area is the availability of farmland and proximity to the city.

For the purpose of this study, five farm settlements were randomly selected to represent the study population. Using proportionate sampling technique, 300 respondents were selected from the five farm settlements.

A set of structured questionnaire consisting of two sections was used to elicit information from the respondents. Section A solicited for the respondents' background information while section B contains three items which were used to elicit information on knowledge of malaria, knowledge of the preventive strategies and the practice of the preventive strategies. The questionnaire was adapted from Marthar, Khokhar and Sachdev (2004) in a study on assessment of knowledge about malaria among patients reported with fever: a hospital based study.
In determining the knowledge, the questionnaire employed Yes, No and I don't know rating scale while for determining the practice it employed a 4-point response scale of frequently with 4 points, sometimes (3 points), rarely (2 points) and never (1 point). Administration of the instrument was carried out by the researchers with the aid of trained research assistants who also interpreted the items in the instrument to local languages to the respondents who did not understand English Language to ensure maximum comprehension. A total of 300 questionnaires were administered and retrieved.

\section{RESULTS}

Table 1: Knowledge of malaria related issues

\begin{tabular}{|c|c|c|c|c|}
\hline Malaria & Yes & $\%$ & No & $\%$ \\
\hline $\begin{array}{l}\text { is a disease caused by } \\
\text { mosquitoes }\end{array}$ & 225 & 75 & 75 & 25 \\
\hline $\begin{array}{l}\text { is transmitted by mosquito } \\
\text { bites }\end{array}$ & 252 & 84 & 48 & 16 \\
\hline can be prevented & 258 & 86 & 42 & 14 \\
\hline $\begin{array}{l}\text { is best treated by medical } \\
\text { doctor }\end{array}$ & 252 & 84 & 48 & 16 \\
\hline manifests with fever & 255 & 85 & 45 & 15 \\
\hline $\begin{array}{l}\text { manifests } \\
\text { headache/body pains }\end{array}$ & 255 & 85 & 45 & 15 \\
\hline $\begin{array}{l}\text { manifests with body } \\
\text { weakness }\end{array}$ & 252 & 84 & 48 & 16 \\
\hline $\begin{array}{l}\text { can result into } \\
\text { complication like shortage } \\
\text { of blood }\end{array}$ & 186 & 62 & 114 & 38 \\
\hline $\begin{array}{l}\text { can prevent one from } \\
\text { working }\end{array}$ & 189 & 63 & 111 & 37 \\
\hline can result into death & 192 & 64 & 108 & 36 \\
\hline $\begin{array}{l}\text { one must go to the health } \\
\text { centre to be treated for } \\
\text { malaria }\end{array}$ & 210 & 70 & 90 & 30 \\
\hline
\end{tabular}

Table 1 shows the percentages of responses to the questions on malaria and malaria related issues. The participants possessed moderate to high level of knowledge in all aspects of malaria. Majority of respondents (86\%) knew that imalaria could be prevented but knowledge on complication of malaria had the least score as only $62 \%$ knew that malaria can result into shortage of blood.. 
Table 2: knowledge of malaria preventive strategies

\begin{tabular}{|l|l|l|l|l|}
\hline Preventive measures & Yes & $\%$ & No & $\%$ \\
\hline $\begin{array}{l}\text { Cutting bushes around } \\
\text { residential areas }\end{array}$ & 255 & 85 & 45 & 15 \\
\hline $\begin{array}{l}\text { Removing containers that } \\
\text { can hold water where } \\
\text { mosquito can breed }\end{array}$ & 276 & 92 & 24 & 8 \\
\hline $\begin{array}{l}\text { Sleeping inside mosquito } \\
\text { nets }\end{array}$ & 264 & 88 & 36 & 12 \\
\hline Using window nets & 243 & 81 & 57 & 19 \\
\hline $\begin{array}{l}\text { Using protective clothing } \\
\text { when outside at night }\end{array}$ & 237 & 79 & 63 & 21 \\
\hline $\begin{array}{l}\text { Using mosquito } \\
\text { insecticides mosquito }\end{array}$ & 255 & 85 & 45 & 15 \\
\hline $\begin{array}{l}\text { Using prophylactic } \\
\text { repellants }\end{array}$ & 177 & 59 & 123 & 41 \\
\hline $\begin{array}{l}\text { Using of prop } \\
\text { malaria drugs }\end{array}$ & 90 & 30 \\
\hline
\end{tabular}

Table 2 shows that the participants have moderate to high level of knowledge on malaria preventive strategies. Respondents demonstrated highest knowledge (92\%) in the statement that removing containers that can hold water where mosquito can breed can prevent malaria. On the other hand, participants' response on the statement that use of mosquito repellants can prevent malaria though demonstrated a moderate level of knowledge (70\%) was the least.

\section{TESTING OF HYPOTHESES}

In order to determine if the difference observed in all the identified factors with respect to knowledge of malaria and preventive strategies are statistically significant, a t-test analysis was used.

Hypothesis 1: There is no significant difference between knowledge of malaria and knowledge of the preventive strategies among migrant farmers in the study area.

Table 3: Comparison (by t-test) knowledge of malaria and Knowledge of the preventive strategies.

\begin{tabular}{|c|c|c|c|c|c|c|c|}
\hline & $\mathbf{N}$ & $-\bar{x}$ & SD & DF & t cal & $t$ tab & Sig \\
\hline Knowledge of malaria & 300 & 18.4 & 3.61 & 299 & $14.04^{*}$ & 1.96 & Sig. \\
\hline $\begin{array}{l}\text { Knowledge of malaria } \\
\text { preventive strategies }\end{array}$ & 300 & 14.2 & 2.6 & & & & \\
\hline
\end{tabular}

*Significant at $\mathrm{p}>0.05$

In table 3 , the calculated $t$ value of 14.04 is greater than the table value of 1.96 . Thus, the null hypothesis is rejected and therefore conclude that there is a significant difference between knowledge of malaria and knowledge preventive strategies among migrant farmers in the study area.
Hypothesis 2: There is no significant difference between the knowledge of malaria and the practice of malaria preventive strategies among migrant farmers in the study area.

Table 4: knowledge of malaria and practice of malaria preventive strategies

\begin{tabular}{|c|c|c|c|c|c|c|c|}
\hline & $\mathbf{N}$ & $-x$ & SD & DF & $\mathrm{t}$ cal & $t$ tab & Sig. \\
\hline Knowledge of malaria & 300 & 18.4 & 3.61 & \multirow[t]{2}{*}{299} & \multirow[t]{2}{*}{$28.02^{\star}$} & \multirow[t]{2}{*}{1.96} & \multirow[t]{2}{*}{ Sig. } \\
\hline $\begin{array}{l}\text { Practice of } \\
\text { malaria preventive strategies }\end{array}$ & 300 & 33.3 & 6.56 & & & & \\
\hline
\end{tabular}

*Significant at $p>0.05$ 
In table 4 , the $t$ calculated value (28.02) is greater than the table value (2.21). The null hypothesis is therefore rejected. Thus, there is significant difference between the knowledge of malaria and the practice of malaria preventive strategies among migrant farmers in the study area.

Hypothesis 3: Educational status has no significant influence on the practice of malaria preventive strategies of migrant farmers in the study area.

Table 5: Educational status and practice of malaria preventive strategies

\begin{tabular}{|l|l|l|l|l|l|l|}
\hline $\begin{array}{l}\text { Age } \\
\text { groups }\end{array}$ & ss & ms & df & F-cal & $\begin{array}{l}\text { F- } \\
\text { tab }\end{array}$ & Sig. \\
\hline $\begin{array}{l}\text { Between } \\
\text { groups }\end{array}$ & 495.840 & 123.960 & 4 & $6.17^{*}$ & 2.37 & Sig. \\
\cline { 1 - 4 } $\begin{array}{l}\text { Within } \\
\text { group }\end{array}$ & 5923.820 & 20.08 & 295 & & & \\
\cline { 1 - 4 } Total & 6419.660 & & 299 & & & \\
\hline
\end{tabular}

In table 5 , the F-calculated value of 6.17 is higher than the table value of 2.37. Therefore the null hypothesis was rejected. Thus, educational status of the respondents has significant influence in the practice of malaria preventive strategies among migrant farmers in the study area.

\section{DISCUSSION}

Findings that majority of the migrant farmers knew that malaria is transmitted by mosquitoes agreed with the findings of Batega (2004) that $80-90 \%$ have the knowledge of the cause of malaria though Udonwa, Gyuse and Etokidem (2010) gave a contrary report . The researchers in their surveys discovered lack of knowledge and many misconceptions about the transmission of malaria. The findings that majority of the migrant farmers (86\%) knew that malaria disease can be prevented agreed with Rissa (2000) where $87.5 \%$ of a community knew that malaria can be prevented. Though, the discovery that $64 \%$ of the migrant farmers knew that malaria can result to death negates the findings of Rissa (2000) where 95.4\% saw malaria as a severe problem that could kill.

On the method of malaria prevention in the study area, the general knowledge of the respondents was high which agreed with the report of Oyewole and Ibidapo (2007) but disagreed with the findings of Fawole and Onyeaso (2008) who discovered that the knowledge on malaria possessed by respondents was poor. The fact that the respondents were aware that removing containers that can hold water where mosquitoes can breed and bush clearing as a control measure agreed with the findings of Erhun, Agbani and Adesanya (2005) but disagreed with Udonwa et.al (2010) where very few of the participants knew that clearing of the vegetation in and around their domestic environment would prevent malaria.

The significant difference in the knowledge of malaria and preventive strategies denoted that majority of the respondents had knowledge of malaria but lacked knowledge of the preventive strategies. This corroborates with the findings of Vundule and Mharakurwa (1996) in their study in Zimbabwe which showed that there was no significant relationship between people's knowledge of the causes of malaria and the knowledge of preventive measures. Similarly. and that a household's level of understanding of the purpose of bush clearing and a serene environment was contrary to living a healthy life as a result of malaria prevention in the area.

The significant difference in the knowledge of malaria and the practice of malaria preventive strategies agrees with the findings of Khan et al (2010) where greater knowledge about malaria causation, symptoms and prevention does not translate to improved practice of malaria preventive measures. It is interesting that the finding of the study contradicts those of Erhun et al.(2005) and Seck, Fall, Faye, Ba and Tal Dai (2008) who discovered that there was a high correlation between knowledge and practices of malaria preventive strategies.

The knowledge of the respondents on malaria could be attributed to the recently concluded awareness programme on malaria and distribution of Long Lasting Insecticides Nets (LLINS) done by Yakubu Gowon Foundations in collaboration with the Federal Ministry of Health in 2009 where each household was reached but it seems as if the knowledge gained does not translate to practice of the preventive measures.

Finally, the findings of this study on the influence of educational status and practice of malaria preventive strategies agreed with the study conducted in Malawi by Ziba, Slutsker, Chitsulo and Steketee (1994) where educational status was found to be a significant predictor of practices of malaria prevention strategies but differ from the findings of Sharma et al. (2007). The explanation to this as revealed in the study is that those with high educational status were in better position economically to practice malaria prevention strategies. This corroborates the findings 
of Legesse et al (2010) in their research on the knowledge of mode of transmission and preventive measures of malaria in Western Ethiopia where they discovered that educational and wealth status of respondents were associated with practice of malaria preventive measure. Thus, educational and wealth status of respondents on malaria preventive measures in western Ethiopia was significantly higher among those who completed colleges and universities, those in well-off quintile, and respondents from Menge town compared to those who have no formal education or have not completed their college/university education, those in the poorest wealth quintiles and those from Assosa town. This indicates that the level of education of respondents in the study area affect the practice of malaria preventive strategies.

\section{CONCLUSION}

Based on the findings of this study, it can be concluded that the respondents were familiar with causes of malaria and the necessary preventive strategies. It was equally found that educational status of participants influenced the practices of malaria preventive strategies.

\section{RECOMMENDATIONS}

In view of the findings, it is being recommended that the Government should promote efforts that will improve the knowledge of migrant farmers in their locality on malaria preventive strategies. The use of mass media by health educators in disseminating information on malaria preventive strategies would be useful in creating awareness on malaria and the preventive strategies. The Government should introduce information on malaria preventive measures into the curriculum of basic and secondary school systems. Periodic monitoring and sensitization programmes should be done by health workers to ensure the practice of malaria preventive strategies by migrant farmers.

\section{REFERENCES}

Batega, D.W. (2004): Knowledge attitudes and practices about malaria treatment and prevention in Uganda. $A$ Lliterature Review Final Report. pdf.usaid.gov/pdf.docs/PNADU090.pdf. Retrieved April 25, 2011.

Erhun, W.O., Agbani, E.O. \& Adesanya, S.O. (2005): Malaria prevention: Knowledge, attitude and practice in a south western Nigerian community. African Journal of Biomedical Research. 8(1): 25 - 29
Fawole, A.O. \& Onyeaso, N.C. (2008): Perception and practice of malaria prophylaxis among primary health care providers in Ibadan. West African Journal of Medicine. 27 (2). 92-96.

IRIN (2011): Killer Number one: the fight against malaria. Humanitarian News and analysis. www.irinnews.org/InDepthMain,aspx?InDepthld (Retrieved, May 18, 2011)

Johansson, E.W., Renshaw,M. \& Wardlaw, T.(2009): Malaria and Children Progress Intervention. New York. United Nations Children's Fund (UNICEF) Report.

Khan, J.S., Usman, M., Abbass, Y., Hussain, M, \& Alli, M. (2010) Knowledge, attitude and Practice study on malaria. Gomal Journal of Medical Sciences. 8(2).204208

Kinung'hi, S. M., Mashauri, F., Nwanga, J.R., Nnko,S.E., Kaatano, G.M., Malima, R., Kishamawe, C., Magesa, S. \& Mboera, L.E.G (2010): Knowledge, attitudes and practices about malaria among communities: Comparing epidemics and non-epidemic prone communities of Muleba District, Northwestern Tanzania. BMC Public Health. www.biomedcentral.com.Retrieved April 22, 2011.

Legesse, Y., Tegean, A., Belachew T. \& Tushune K. (2010): Knowledge about mode of transmission and preventive measures of malaria. Ethiopia Journal of Health Development. 21(2); 157 - 165

Lucas and Gilles (2002): Malaria: Short Textbook on Public Health Medicine for the Tropics. India, Arnold Publication.

Matta, S., Khokhar, A. \& Sachdev, T.R. (2004): Assessment of Knowledge about Malaria among Patients Reported with Fever. A Hospital Based Study. Journal on Vector Borne Diseases. 41, 27-31.

Mazigo, D.M., Obasy, E., Mauka, W., Manyiri, P., Zinga, M., Kweka, E.J., Mnyone, L.L. \& Heukelbach, J. (2010): Knowledge, Attitudes and Practices about Malaria and its control in Rural Northwest Tanzania. Malaria Research and Treatment. doi:10.4061/2010/794261

Oyewole, I. O. \& Ibidapo, A. C. (2007): Attitudes to malaria, prevention, treatment and management strategies associated with the prevalence of malaria in a Nigerian urban centre. African Journal of Biotechnology. 6 (21); 2424-2427.

Riisa, F. (2000): KAP regarding prevention of malaria by mothers/caretakers in Bumozi Parish, Mbigi District. Unpublished dissertation submitted to Department of Nursing, Medical School. University of Makerere.

Seck, I., Fall, I.S., Faye, A. Ba, O. \& Tal Dai, A. (2008): Malaria knowledge, attitudes and practices among 
Am. J. Sci. Ind. Res., 2011, 2(6): 883-889

women living in rural Poponguine, Senegal. Medecine Tropicale. (Mars). 68(6): 629-633.

Sharma, A.K., Bhasin, S. \& Chaturvedi, S. (2007): Predictors of Knowledge about Malaria in India. Journal on Vector Borne Diseases. 44. 189-1197

Udonwa, N.E., Gyuse, A.N. \& Etokidem, A.J. (2010): Malaria: Knowledge and Prevention Practices among school adolescents in a coastal community in Calabar, Nigeria. Africa Journal of Primary Health and Family Medicine.2 (1) www.ghdonline.org/malaria/resource. (Retrieved April 20, 2011)
Van Gendermalsen, A. A. \& Munochiveyi, R. (1995): Knowledge, attitude and practice relating to malaria in Mashonaland Central, Zimbabwe. Central African Journal of Medicine. 41(1); 10-14

Vundule, C. \& Mharakurwa, S. (1996): Knowledge, practice and perceptions about malaria in rural communities of Zimbabwe: Relevance to malaria control. Bulletin of world health organization, 74(1). $55-60$

Ziba, C., Slutsker, L., Chitsulo. L. \& Steketee, R.W. (1994): Use of malaria prevention measures in Malawian households. Tropical Medical Parasitology 45(1); 70 73 